\title{
Um Deus com o rosto do Brasil: um estudo exploratório sobre a relação entre imagens e imaginários de Deus na cultura e na pregação evangélico-luterana
}

\author{
A God with the face of Brazil: an exploratory study on the relationship \\ between images and imaginary of God in the culture and in the Evangelical \\ Lutheran preaching
}

Júlio Cézar Adam*

\begin{abstract}
Resumo
Este artigo pretende refletir sobre imagens e imaginários de Deus no contexto brasileiro em relação com imagens e imaginários de Deus em prédicas do contexto latino-americano, tomando como exemplo prédicas escritas por ministros/as da Igreja Evangélica de Confissão Luterana no Brasil (IECLB), publicadas no site Göttinger Predigten im Internet. Para análise destas imagens e imaginários de Deus, julgou-se importante, tratar o contexto sociocultural da IECLB - que corresponde, em grande medida, ao contexto do protestantismo histórico no Brasil - e refletir brevemente sobre imagem e imaginário em relação à religião e à teologia, não pretendendo construir uma teoria sobre imagem e imaginário. $\mathrm{O}$ artigo divide-se em três partes: na primeira parte apresentam-se aspectos das imagens e dos imaginários de Deus presentes na cultura e religiosidade brasileira, tomando alguns exemplos da cultura pop e do contexto teológico de alguns segmentos eclesiásticos. Na segunda parte, busca-se brevemente por conceitos de imagem, imaginário, averiguando a sua relação com a teologia. Na última parte, analisam-se imagens de Deus em prédicas da IECLB e busca-se refletir sobre o significado destas imagens para a pregação cristã, considerando-se o contexto em que a igreja está inserida.
\end{abstract}

Palavras-chave: imagem de Deus; imaginário de Deus; cultura brasileira; religiosidade brasileira; imagem de Deus na prédica; IECLB

\begin{abstract}
This article aims to reflect on the images and the imagery of God in the Brazilian context in relation to images and imaginary God in the preaching of the Latin American context, taking as example sermons written by ministers of the Evangelical Church of Lutheran Confession in Brazil (IECLB) published on the site Göttinger Predigten im Internet. For analysis of these images and the imagery of God, it was deemed important to treat the socio-cultural context of the IECLB - which corresponds largely to the context of the historical Protestantism in Brazil - and reflect briefly on image and imagery in relation to religion and theology, not intending to build a theory of image and imagery. The article is divided into three parts: the first part presents aspects of images and imagery of God present in Brazilian culture and religiosity, using a few examples of pop culture and theological context of some ecclesiastical segments. In the second part, we seek briefly for concepts of image, imagination and verify the relationship with theology. In the last part, it analyzes images of God in the preaching of the IECLB and seeks to reflect on the meaning of these images to the Christian preaching, considering the context in which the church is located.
\end{abstract}

Keywords: image of God; imagery of God; Brazilian culture; Brazilian religiosity; images of God in the preaching; IECLB

Artigo submetido em 05 de janeiro de 2016 e aprovado em 28 de novembro de 2016.

* Doutor em Teologia pela Universidade de Hamburgo, Alemanha (2004), membro da International Academy of Practical Theology (IAPT), professor de Teologia do PPG em Teologia da EST. País de Origem: Brasil. E-mail: julioadam@est.edu.br

Horizonte, Belo Horizonte, v. 14, n. 44, p. 1298-1322, out./dez. 2016 - ISSN 2175-5841 


\section{Introdução}

Este artigo tem como objetivo analisar de forma exploratória imagens e imaginários de Deus presentes no contexto cultural e religioso brasileiro e estabelecer uma relação com imagens e imaginários de Deus presentes no discurso homilético de uma igreja pertencente ao protestantismo histórico brasileiro, no caso a Igreja Evangélica de Confissão Luterana no Brasil, a IECLB, propondo, assim, um diálogo entre narrativa sagrada e linguagem religiosa. Trata-se, portanto, de uma reflexão relacionada à Teologia Prática, de forma mais específica, à homilética. Sabe-se que para o protestantismo a Palavra veiculada por meio da pregação foi uma marca constitutiva. O discurso e sua compreensão - o ouvir constitui-se condição fundamental para o acesso e o fortalecimento da fé. Os ritos, inclusive os sacramentos, e, de maneira mais radical, as imagens ficaram para um segundo plano, quando não banidas da vida espiritual e litúrgica da igreja. A Palavra e a prédica, porém, como linguagem, não conseguem prescindir das imagens e dos imaginários. Em um contexto, como o brasileiro, onde a cultura, a fé e a religiosidade são fortemente influenciadas pela matriz Católico-Romana e pelas formas híbridas e sincréticas da religiosidade, imagens e imaginários de Deus impregnam o contexto, a cultura e o cotidiano das pessoas, também daquelas pertencentes ao protestantismo.

Em que medida essas imagens e esses imaginários de Deus presentes na cultura influenciam as imagens de Deus nas prédicas da IECLB, torna-se a pergunta principal deste artigo. Por isso, dividiu-se o estudo em três grandes partes. Na primeira parte, se apresenta de forma exploratória aspectos do contexto e da cultura onde a IECLB está inserida, apresentando imagens e imaginários de Deus presentes na cultura pop, como no cinema, p. ex, e em teologias e segmentos eclesiásticos, como a imagem de Deus na ilustração “O caminho largo e o caminho estreito" e nos Cristos crucificados da Teologia da Libertação, p. ex. Na segunda parte do artigo, busca-se por conceitos de imagem e imaginário, tomando principalmente como base desta reflexão um texto de Francis Wolff. Não se 
pretende aqui desenvolver uma teoria conceitual de imagem e imaginário, mas sim apresentar alguns pressupostos para a reflexão. Construída esta base contextual e conceitual, parte-se para a análise de imagens de Deus presentes em nove prédicas de pastores e pastoras da IECLB, no site Göttinger Predigten im Internet. ${ }^{1}$ Trata-se de um site onde deliberadamente pastores/as da IECLB são convidados a publicar suas prédicas, em português, fato que facilitou o acesso aos textos escritos das prédicas. As prédicas foram escolhidas a partir de três critérios básicos: textos bíblicos do Antigo e do Novo Testamento de diferentes tipos - Pentateuco, Profetas, Evangelho e Epístola; textos que em si apresentam imagens de Deus; pelo menos um terço das prédicas escolhidas foram escritas por pastoras, propiciando, assim, uma relativa consideração a partir do gênero. Não se pretende, portanto, desenvolver um estudo profundo sobre imagens e imaginários de Deus nas prédicas da IECLB, mas fazer um estudo exploratório, tomando algumas prédicas como exemplo. Nas prédicas, analisam-se, simplesmente, formas como Deus (Pai, Filho e Espírito Santo) é descrito. Surpreende, na interpretação final destas imagens descritas, o quanto estas diferem das imagens de Deus presentes na cultura e no contexto brasileiro. As imagens de Deus presentes nas prédicas reproduzem um Deus bíblico-teologicamente "correto", porém distante da vida concreta das pessoas e das comunidades eclesiásticas. Como relacionar estas imagens teológicas de Deus com as imagens da cultura e do contexto, permanece uma frase em aberto, tanto para a homilética, quanto para a Teologia Prática e a Teologia.

\section{Imagens de Deus na cultura e no imaginário brasileiro}

A proibição da imagem de Deus foi levada muito a sério no Brasil: na Igreja, instituição e na Teologia oficial. Na cultura e na religiosidade popular, porém, Deus é imaginado e pintado de muitas maneiras. Famosa no Brasil é a expressão "Deus é

\footnotetext{
${ }^{1}$ http://www.predigten.uni-goettingen.de/index.php?sprache=de
} 
brasileiro"2, uma forma talvez de aproximar o deus "oficial", "correto" e "distante" da Igreja da cultura, do povo e do dia-a-dia. O Deus Brasileiro ganha muitas formas e configurações, principalmente no imaginário do povo.

Deus desfila independentemente das doutrinas e dos dogmas da teologia oficial na cultura popular: música, literatura, cinema, festas, futebol e na mídia. Quem é e como é a imagem deste Deus? Como o Deus Brasileiro é pintado e imaginado? Sem dúvida trata-se de um Deus sincrético e híbrido, que corresponde a tendências da própria cultura brasileira. No estudo do antropólogo holandês André Droogers, ainda na década de 80, apontou-se para este Deus diferente. Enquanto na religião e nas religiosidades institucionais Deus está distante, nas representações da cultura popular Deus se mostra próximo. "Ele atua através de intermediários, como Jesus, a Virgem Maria, santos, espíritos ou orixás, que são, de fato, os verdadeiros objetos da devoção e da atividade ritual”. [...] Ele é quem ajuda, abençoa, ilumina, acompanha e protege" (DROOGERS, 1987, p. 76).

Qual imagem plástica se faz deste Deus? Fazendo uma busca no Google Imagens a partir do termo "Deus", a maioria das imagens que surgem são de nuvens, sol, horizonte, natureza, com ou sem a palavra "Deus" ou, então, imagens de Jesus Cristo. A outra imagem, mais recorrente, sobretudo em charges e desenhos a respeito de Deus, e que talvez seja a imagem mais comum para Deus no Brasil, é a do velho de barbas brancas sentado num trono, no céu, sobre uma nuvem, olhando e controlando a vida na terra (ARAÚJO, 2012, p. 69).

Segundo João Dias Araújo, a imagem do "Deus brasileiro" se constrói por meio de uma inculturação sincrética. Se busca em Tupã, o deus do trovão indígena, o deus que dá medo. Essa imagem foi usada, p. ex., pelos catequistas jesuítas, como forma de catequisar os indígenas; se busca em Olorum, deus africano, o reforço para uma ideia de Deus criador, supremo, mas distante da criação e da criatura; e se busca em Jesus Cristo e em Maria uma imagem de bondade e compaixão em

\footnotetext{
2 Inquerido sobre a rivalidade entre argentinos e brasileiros, presente no futebol, o Papa Francisco, consola em forma de brincadeira dizendo: "Vocês têm agora um Papa argentino, mas Deus é brasileiro".
} 
relação ao divino. Segundo Araújo, essa construção inculturada e sincrética levou a uma imagem de Deus estranha no imaginário3 cultural brasileiro. Deus é, por um lado, imaginado como pai bonachão, de bondade exagerada, como Papai Noel (Ditado: Deus é pai, não é padrasto). Este Deus bonachão "vem gingar com o povo, nas ruas da cidade, durante o Carnaval e participar de todos os deboches e inconveniências" (ARAÚJO, 2012, p. 70).4 Por outro lado, esse Deus bonachão aparece como um Deus mau, que castiga os seus filhos (Ditado: Deus não mata, mas castiga). E, ainda, uma terceira nuance, aponta para uma imagem de Deus como um ser distante, aristocrata, de difícil acesso, e um Deus indiferente, que deixa as pessoas entregues à própria sorte e destino, gerando, por vezes, uma atitude fatalista no imaginário popular (Ditado: Se Deus quiser. Ou: Só Deus sabe o dia de amanhã) (ARAÚJO, 2012, p. 67-71).

Outra construção imagética relaciona Deus a comportamentos e atitudes típicos do ser humano brasileiro. Em um estudo sobre religião e gênero no cinema brasileiro, Carolina T. Lemos, professora da PUC de Goiás, analisa a imagem de Deus no filme "Deus é Brasileiro" (Cacá Diegues, Brasil, 2003) e o "Auto da Compadecida" (Guel Arraes, Brasil, 2000). Ambos os filmes são baseados em literatura de dois importantes escritores brasileiros: Deus é Brasileiro é baseado no conto de João Ubaldo Ribeiro “O santo que não acreditava em Deus”, e o "Auto da Compadecida" é baseado na obra homônima de Ariano Suassuna. No primeiro caso, segundo Lemos, Deus, "o criador do universo, uma figura masculina representada pelo ator Antônio Fagundes, atravessa todo o filme resmungando e ridicularizando seus companheiros de viagem, como se tudo não passasse de um imenso incômodo. [...] um Deus com coração de pai, um tanto mal-humorado com o que seus filhos têm feito aqui na terra. [...] um Deus com perfil de patriarca que se autoriza a mandar e reclamar de tudo e de todos o tempo todo" (LEMOS, 2012. p. 59). No segundo filme, como o próprio nome já indica, Deus dá lugar à

\footnotetext{
${ }^{3} \mathrm{O}$ conceito de imaginário deste artigo definir-se-á no próximo tópico.

${ }^{4}$ A música de Jammil "We are Carnaval" dirá: "Vai compreender que o baiano é um povo a mais de mil. Ele tem Deus no seu coração e o Diabo no quadril”.
} 
compadecida, Nossa Senhora, Maria. Deus é tão distante que não aparece no enredo. As figuras divinas são Maria, Jesus, que no filme é um negro, e o diabo, ambas figuras muito presentes no imaginário da cultura e das religiosidades brasileiras. Segundo Lemos, a figura materna de Maria toma aqui o lugar de Deus. Maria é a mãe que se compadece do ser humano, reforçando o papel da mulhermãe, generosa por natureza. Além disso, a Compadecida, no lugar de Deus, é aquela que desculpa, dá um jeito de justificar os erros e pecados dos personagens, livrando todos dos castigos do inferno. A Compadecida dá um “jeitinho”, burlando e corrompendo regras e princípios, algo muito presente na cultura e sociedade brasileira e nas diferentes formas de corrupção. 5

No campo da religião e da religiosidade popular, o Brasil se caracteriza por uma exuberância de imagens de Cristos e de santos, numa complexa amalgação de tradições, ritos, gestos, imagens artefatos e espaços (RENDERS, 2015. p. 64), que povoam não só os altares e as naves dos tempos barrocos e modernos, mas também as ruas e as casas das pessoas (COSTA; PASSOS, 2011, p. 123-134). Não por acaso, um dos principais cartões postais do Brasil é o Cristo, na cidade do Rio de Janeiro. Essa exuberância - diria que se trata, por vezes, de um excesso - de imagens de Cristos, santos, Marias, sacerdotes, religiosos, em forma de pintura, escultura, tapetes (procissão de Corpus Christi), imagens impressas, replicadas através do sincretismo com as tradições afro e indígenas, encontra no catolicismo institucional e romanizado, com seu discurso dogmático e racionalizado a respeito de Deus, uma forma de reação (pouco efetiva?). ${ }^{6}$

Outra forma de reação a essa exuberância e esse excesso de imagens e ao culto popular às imagens, fará o protestantismo brasileiro, tanto o de missão quanto o de imigração, nas configurações teológicas e eclesiais mais diversas

\footnotetext{
${ }^{5}$ Sobre a malandragem e o "jeitinho" como marcas da cultura e sociedade brasileira, ver DAMATTA, Roberto. Carnavais, malandros e heróis: para uma sociologia do dilema brasileiro. Rio de Janeiro: Rocco, 1997.

${ }^{6}$ Ver, p. ex., STEIL, Carlos A. O sertão das romarias: um estudo antropológico sobre o santuário de Bom Jesus da Lapa. Petrópolis: Vozes, 1996.
} 
(CUNHA, 2012, p. 173ss). O protestantismo brasileiro se caracteriza por uma radical sobriedade e negação em relação às imagens e aos símbolos religiosos.

Cunha, refletindo, não especificamente sobre imagens de Deus no protestantismo, mas sobre os evangélicos no Brasil, resgata em seu texto uma ilustração de Deus, muito presente em casas e templos evangélicos do Brasil. Tratase do quadro "Os dois caminhos" ou "O caminho largo e o caminho estreito (CUNHA, 2012, p. 175), importado possivelmente da Europa, por volta da primeira década do século XX. Segundo Cunha, essa imagem reflete não só uma imagem Deus, mas "a teologia que forma o mundo evangélico brasileiro, arminianapietista-puritana, milenarista e fundamentalista, baseada numa dualidade de dois caminhos que se impõe como uma escolha a ser feita" (CUNHA, 2012, p. 174s.). No quadro, Deus é representado como o triângulo, distante, no alto, no céu, com um olho no centro, e três raios que irradiam da figura.

Após amplo processo de desenvolvimento teológico, como abertura à esfera pública, responsabilidade social, diálogo ecumênico ao longo do século XX (CUNHA, 2012, p. 176s.), certamente esta imagem estática e dura de Deus tenha mudado no meio evangélico. Em que medida ela se mantém ainda presente no imaginário e na pregação evangélica, é algo que veremos adiante.7

Outro imaginário religioso que se criou no contexto brasileiro e latinoamericano tem a ver com os desenvolvimentos da Teologia da Libertação (TdL) a partir da década de 60 (séc. XX). A TdL surge como uma forma clara de nomear a realidade e denunciar a vulnerabilidade histórica e estrutural do contexto. Inspirada dentre outras nas teologias da esperança (J. Moltmann) e na teologia política (J. B. Metz), e gestada na Conferência Episcopal Latino-Americana (CELAM), da Igreja Católica, em Medelin e Puebla, a TdL nasce como opção pelos pobres, propondo uma teologia claramente voltada para o contexto de

\footnotetext{
${ }^{7} \mathrm{O}$ amplo e complexo desenvolvimento das imagens e imaginários de Deus no universo pentecostal e neopentecostal não poderá ser avaliado neste artigo. Interessante nesta abordagem é o livro: CAMPOS, Leonido Silveira. Teatro, templo e mercado: organização e marketing de um empreendimento neopentecostal. 2. Ed. Petrópolis/São Paulo/São Bernardo do Campo: Vozes/Simpósio/UMESP, 1999.
} 
vulnerabilidade. Em meio a um contexto de ditaduras militares articuladas contra a organizações populares e de esquerda política, a TdL elabora uma nova cristologia, que, consequentemente, vai gerar uma nova eclesiologia, as comunidades eclesiais de base $(\mathrm{CEBs})^{8}$, onde a práxis de libertação e o método ver-julgar e agir, provocariam grandes mudanças, na sociedade, mas principalmente na igreja e na própria teologia. Consequentemente, sua igreja é uma igreja que se faz povo, a igreja dos pobres, uma igreja incorporada na vida dos pobres. Jesus Cristo é encontrado no rosto do pobre. Essa compreensão irá gerar uma iconografia e um imaginário muito próprios. Deus vai ser imaginado como gente, como povo, como pobre. Aqui, Deus não só se aproxima, mas assume a condição e as feições do pobre.

São muitas as imagens do Cristo crucificado que dão vasão a essa nova visão. Um dos tantos exemplos é a impactante escultura do Cristo Torturado ${ }^{9}$, do artista brasileiro Guido Rocha. ${ }^{10}$ Guido Rocha foi um militante político, preso e torturado pela ditadura militar do Brasil, nas décadas de 60 e 70. A partir dessa experiência horrenda, o artista fez com que todos os seus Cristos apresentassem características faciais semelhantes às expressões dos companheiros assassinados ou torturados, assim como dos rostos de camponeses pobres. Assim fala o artista: “A gente tinha a impressão que as ancas, as costas, o coração e os pulmões estavam à mostra. Então eu me pus a detalhar o rosto e cada vez mais o crucificado tomava um aspecto rebelde".11 Mesmo confessando-se não religioso, o artista projetou nas figuras do Cristo todo o imaginário de resistência, denúncia, rebeldia e contestação, procurando fazer justiça tanto à sua experiência pessoal e às tragédias que se abateram sobre sua vida, quanto às misérias e aos sofrimentos seculares vividos

\footnotetext{
${ }^{8}$ Sobre as CEBs ver: TEIXEIRA, Faustino L. C. A gênese das CEBs no Brasil: elementos explicativos. São Paulo: Paulinas, 1988.

${ }^{9}$ A obra do Cristo Torturado, de 1975, é uma de suas esculturas, com mais de dois metros de comprimento, exposta no Centro de Treinamento da Conferência das Igrejas de toda a África, em Nairóbi, Quênia.

${ }_{10}$ Uma análise teológica sobre esta obra, ver em: ZWETSCH, Roberto E. O Cristo torturado da América Latina: reflexões sobre arte e teologia a partir das esculturas de Guido Rocha. In: SCHAPER, Valério G.; WESTHELLE, Vítor, OLIVEIRA, Kathlen L. de; GROSS, Eduardo (Orgs.). Deuses e ciências na América Latina. São Leopoldo: Oikos/EST, 2012, p. 73-93.

${ }_{11}$ Todas as informações dos depoimentos de Guido Rocha e uma foto da obra de arte podem ser encontradas na sua página da internet: <www. softek.com.br/Guido/Vida.htm> .
} 
pelo povo latino-americano, camponeses, operários, indígenas, afro-americanos e outros setores da sociedade.

Nas últimas décadas, a TdL se abre para novos apelos de libertação, como as questões de gênero, questão indígena, questão dos afrodescendentes, questão do pluralismo religioso, questão ecológica, assumindo a nomenclatura plural de Teologias Latino-Americanas da Libertação, com novos imaginários e figuras para representar e expressar Deus. Claudete Beise Ulrich tem investigado esse tema, verificando novas representações do Cristo crucificado no contexto latinoamericano, como base para pensar uma teologia da ressurreição no contexto (BEISE ULRICH). Segundo ela, não apenas o pobre e o torturado ganham espaço na cruz, mas a mulher, a indígena, a negra, com seus corpos, ou a própria natureza explorada e morta, ganham forma. Diferente do Cristo morto, tão presente nas procissões do catolicismo as expressões do Cristo crucificado nos diferentes corpos vulneráveis, são um claro protesto profético e um claro anúncio da ressurreição.

Eu entendo assim, que neste contexto a Teologia da Cruz aponta para uma nova realidade sócio-política. Ela aponta para a graça da ressurreição, e comprometemo-nos com um novo mundo de paz e justiça. Um outro mundo é possível. O Crucificado e o Ressuscitado apontam para essa realidade na América Latina (BEISE ULRICH, p. 9).

\section{Ideias sobre imagem, imaginário e teologia}

A primeira questão que se levanta após esta exposição é saber em que medida este universo de muitas imagens de Deus presentes na cultura brasileira impacta no imaginário das pessoas que ouvem a prédica dominical no culto? Em que medida a prédica consegue construir em palavras imagens de Deus tão efetivas quanto as tantas imagens que nos acessam todos os dias? Ou ainda poderíamos perguntar, como podemos subsistir sem representar Deus em imagens em um mundo dominado por imagens?

Não se pretende aqui entrar na longa e complexa discussão sobre a proibição da produção da imagem de Deus no judaísmo (Segundo Mandamento do 
Decálogo), nem tampouco na longa e complexa historização do iconoclasmo na Igreja, sobretudo nos movimentos da Reforma, mesmo considerando que ambos os aspectos são de grande relevância para esta discussão. ${ }^{12}$ Pretende-se, porém, pensar as questões acima a partir de uma compreensão sobre a função da imagem e dos imaginários, e o excesso de imagens no contexto do estudo.

Toma-se como base, principalmente, um texto de Francis Wolff 13 , onde ele discute sobre imagem e seu poder. Segundo Wolff, “a imagem começa a partir do momento em que não vemos mais aquilo que imediatamente é dado no suporte material" (WOLFF, 2005. p. 20). Dizendo de outra forma, a imagem representa algo, tornando presente coisas ausentes. A imagem é, portanto, um substituto. Ela representa aquilo que ela não é. Justamente por isso, para melhor representar, a imagem precisa não se assemelhar demais àquilo que representa. "A imagem constitui uma representação intermediária entre o concreto e o abstrato, o real e o pensado, o sensível e o inteligível” (HIGUET, 2015, p. 18). Por isso, "uma imagem não é uma coisa, é uma relação com outra coisa” (WOLFF, 2005, p. 21). Imagem conta, portanto, com a imaginação. ${ }^{14}$

Wolff diferencia imagem de linguagem. Linguagem, para ele, é a linguagem oral, a palavra. Enquanto a palavra não tem uma relação de similitude com aquilo que diz, a imagem o tem. A imagem assemelha-se aquilo que ela mostra, esta é sua grande virtude. Seu fascínio sobre o ser humano, porém, é decorrência daquilo que ela não pode mostrar, ou seja, o encantamento que a imagem gera no ser humano é decorrência do seu defeito, não da sua virtude. "Com relação à linguagem, a imagem tem na verdade quatro defeitos. [...] a imagem jamais pode dizer: o conceito, a negação, o possível, o passado e o futuro. E são precisamente essas

\footnotetext{
12 Um ótimo estudo sobre desenvolvimento, uso e valores das imagens na Igreja, e seus desdobramentos no contexto midiático atual, encontra-se em KLEIN, Alberto. Imagens de culto e imagens da mídia: interferências midiáticas no cenário religioso. Porto Alegre: Sulina, 2006. p. 49ss. Ver também: FRETTLÖH, Magdalene. Wenn (Schrift-)Worte sich in Bilder einschreiben. Theologische Zeitschrift, Basel, ano 69, n. 3, p. 238-265, 2013.

${ }^{13}$ Francis Wolff é professor na Universidade de Paris X. Lecionou filosofia na Universidade de São Paulo.

${ }^{14}$ Não teremos de desenvolver a questão da imaginação aqui. Vale apenas mencionar sua abertura para sua transgressão da limitação humana: "A imaginação nos abre as portas para um excesso de sentido, mas não nos permite transgredir os limites da nossa finitude pois o conhecimento simbólico não equivale a uma intuição divina, a um saber absoluto" (HIGUET, 2015, p. 27).
} 
quatro impotências que fazem toda a potência da imagem" (WOLFF, 2005, p. 25). Decorre daí grande parte do seu poder de fascinar o ser humano. Segundo Wolff, os dois sistemas - linguagem e imagem - são necessários, porque permitem acessos diferentes à realidade e formas diferentes de comunicá-la e representá-la. “... a humanidade inventou dois sistemas de representação: a linguagem, sonora, temporal, fruto da inteligência, instrumento extremamente sutil, aperfeiçoado, que pode dizer todas as nuances do tempo, do pensamento, do julgamento, todas as modalidades da abstração e da generalidade, mas que não pode tornar verdadeiramente presentes os verdadeiros ausentes, os mortos e os deuses; e o outro sistema, a imagem, visual, espacial, fruto da imaginação, muito mais rudimentar, mas surpreendentemente e impressionante, e que tem o poder mágico de fazer viver os mortos e fazer existir o céu sobre a terra" (WOLFF, 2005, p. 28s.).

Na sua virtude de representar e tornar presente o ausente, as imagens, desde tempos idos (KLEIN, 2006, p. 30ss.), foram utilizadas para representar o absolutamente ausente, o transcendente, Deus. É exatamente nesta pretensão que se cria aquilo que Wolff chama de ilusão da imagem, onde a imagem feita da coisa e a imagem feita pela coisa se confundem (WOLFF, 2005, p. 33). A imagem torna-se o próprio Deus. A proibição de imagens no monoteísmo se contrapõe a essa ilusão da imagem, substituindo as imagens por uma ideia de um deus verdadeiro, imaterial, irrepresentável (WOLFF, 2005, p. 35). Obviamente que esta contraposição não se dá de forma simples, principalmente se considerarmos que a ideia de deus e transcendência há muito não se restringe mais apenas ao âmbito religioso.

Num último desdobramento da imagem, Wolff fala da imagem opaca, a imagem que não apenas representa uma coisa, mas se representa a si mesma como imagem. Cria-se uma nova ilusão, segundo o autor, a mais perigosa, a de não ver mais a própria imagem e de crer ver na imagem a própria realidade, algo perceptível na relação atual com o universo de imagem reproduzido mecanicamente por meio da mídia (WOLFF, 2005, p. 43), algo que será 
amplamente abordado por Guy Debord, no seu estudo sobre a sociedade do espetáculo. ${ }^{15}$ As imagens criam a própria realidade. Os meios tornam-se a própria mensagem, como diria M. McLuhan.

Refletindo sobre imagens mentais, Klein, com base em Morin, irá definir imaginário:

O imaginário dá uma fisionomia não apenas a nossos desejos, nossas aspirações, nossas necessidades, mas também a nossas angústias e temores. Liberta não apenas nossos sonhos de realização e felicidade, mas também nossos monstros interiores, que violam os tabus e as leis, trazem a destruição, a loucura e o terror. Não só delineia o possível e o realizável, mas cria mundo impossíveis e fantásticos (E. Morin) (KLEIN, 2006, p. 40).

O imaginário se forma a partir das imagens concretas da cultura e das imagens mentais, ou seja, das imaginações de grupos e de pessoas. Ao mesmo tempo, o próprio imaginário ganha expressão e formas nas imagens produzidas. Com base em Wunenburger, Etienne Higuet fala de imaginário como algo que remete a uma esfera psíquica onde as imagens adquirem forma e sentido devido à sua natureza simbólica (HIGUET, 2015, p. 22). O imaginário é definido como

conjunto de produções, mentais ou materializadas em obras, com base em imagens visuais (quadro, desenho, fotografia) e linguísticas (metáfora, símbolo, relato), formando conjuntos coerentes e dinâmicos, referentes a uma função simbólica no sentido de um ajuste de sentidos próprios e figurados (WUNENBURGER apud HIGUET, 2015, p. 22).

Teologicamente falando, o não uso de imagens para mostrar, indicar e apontar a Deus é extremamente coerente. Não podemos apreender a Deus. Seria uma grande ilusão. Nem mesmo as palavras com as nuances de tempo, de pensamento, de julgamento, e todas as modalidades da abstração e da generalidade podem dizê-lo. As palavras jamais poderiam torná-lo verdadeiramente presente. A reflexão de Lutero sobre o Deus revelado e crucificado, oculto no subcontrário,

\footnotetext{
15 "El espetáculo se presenta como la sociedad misma y, a la vez como una parte da la sociedad y como un instrumento de unificación" DEBORD, Guy. La sociedade del espetáculo. Valencia: Pre-Textos, 2000. p. 38.
} 
como Palavra dada ao ser humano, caberia muito bem aqui nesta reflexão (EBELING, 1988, p. 180-193). A Palavra, por meio das palavras, permite um espaço de liberdade para imaginar a Deus, espaço que se constitui e se amplia no rico e complexo terreno do símbolo (HIGUET, 2015, p. 24Ss.) ${ }^{16}$, mas, mesmo assim, trata-se de um Deus nunca acessível à nossa razão e pretensão. Apenas em Jesus, o crucificado, temos o máximo da revelação de Deu a nós, absconditus subcontrário, na cruz.

Retomando o questionamento inicial deste ponto, pode-se dizer que imagens e imaginários de Deus são provavelmente muito mais que apenas representações e substituições de Deus. São imagens de Deus que estão arraigadas na cultura e no imaginário brasileiro e que assumem, muitas vezes, a própria realidade de Deus. Pode-se dizer que estas imagens de Deus criadas na cultura e veiculadas em excesso pelas mídias, apesar da nossa teologia, influenciam a maneira como ouvimos a pregação da Palavra. Contaminam a pregação. Falam mais alto do que conceitos e textos, como dirá Helmut Renders (RENDERS, 2015, p. 64). A homilética, como ciência e arte da pregação, deveria levar muito mais a sério essa realidade imagética de Deus. Talvez no exemplo da TdL encontramos formas de expressar Jesus Cristo em uma autêntica teologia da cruz, por meio de imagens - por vezes chocantes e contraditórias - relacionadas a um contexto.

\section{Imagens de Deus nas prédicas da IECLB}

Neste próximo e último passo, pretende-se analisar as imagens de Deus presentes em prédicas da IECLB, e relacionar essas imagens com o exposto acima. Brevemente, pode-se dizer que a Igreja Evangélica de Confissão Luterana no Brasil é uma igreja de imigração, cuja história inicia com a chegada dos primeiros

\footnotetext{
${ }_{16}$ Mais adiante, em sua reflexão, Higuet menciona a compreensão de Cassirer para o simbólico relacionado à imagem e à espiritualidade. "No pensamento de E. Cassirer [...] a imagem será considerada uma forma simbólica pela qual a experiência empírica entre na esfera do sentido. Cassirer questiona a dualidade sensível-inteligível e coloca no princípio da atividade espiritual uma função simbólica pela qual o espírito constrói um primeiro mundo objetivo, dotado de sentido, antes de elevar-se à abstração geral do conceito." (HIGUET, 2015, p. 29).
} 
imigrantes alemães em 1824, principalmente na região sul do Brasil. Os imigrantes protestantes provinham das diferentes tradições da Reforma: luteranos, reformados e unidos, algo que caracteriza até a atualidade a IECLB. A igreja tem atualmente em torno de 715 mil membros, concentrados mais na região sul e sudeste do país. Um desafio permanente desta igreja é seu longo processo de inculturação, a passagem de uma igreja de imigrantes alemães para uma igreja mais integrada no contexto sociocultural brasileiro. ${ }^{17}$ A pregação terá um papel decisivo neste processo.

Para esta análise, tomou-se nove (9) prédicas de pastores/as da IECLB (6 de pastores e 3 de pastoras), publicadas em português no site alemão Göttinger Predigten in Internet. ${ }^{18}$ Como já relatado na introdução, trata-se de um site onde deliberadamente pastores/as da IECLB são convidados a publicar suas prédicas, em português. Isto facilitou o acesso aos textos escritos das prédicas. Por outro lado, perde-se o contexto para o qual as prédicas foram escritas, fato que provavelmente contribui para certo academicismo das prédicas. As prédicas foram escolhidas a partir de três critérios básicos: textos bíblicos do Antigo e do Novo Testamento de diferentes tipos - Pentateuco, Profetas, Evangelho e Epístola (Gênesis, Isaías, Amós, Mateus, João e 1 Coríntios); são textos que em si trazem imagens de Deus; e pelo menos um terço das prédicas escolhidas foram escritas por pastoras, propiciando, assim, uma relativa consideração de gênero. Não se pretende, portanto, desenvolver um estudo profundo sobre imagens e imaginários de Deus nas prédicas da IECLB, mas fazer um estudo exploratório, tomando algumas prédicas como exemplo. Nas prédicas, analisam-se, simplesmente, formas como Deus (Pai, Filho e Espírito Santo) é descrito. As prédicas são de 2008 até 2015. São prédicas curtas, em torno de 1300 palavras. Na maioria são prédicas em formato clássico, expositivas: Texto bíblico - contextualização - atualização aplicação.

\footnotetext{
${ }^{17}$ Evangelische Kirche Lutherischen Bekenntnisses in Brasilien (IECLB), In: http://www.mission-einewelt.de/index.php?id=507. Acessado em 10.06.2012.

${ }^{18} \mathrm{http}: / /$ www.predigten.uni-goettingen.de/
} 
$\mathrm{Na}$ tabela que segue, buscou-se destacar imagens de Deus a partir de atributos, conceitos ou ações de Deus, Jesus Cristo e o Espírito Santo, presentes nas prédicas. O que mais importa, aqui, é a última coluna, sobre as imagens de Deus. Dentro do possível, tomei as expressões a respeito de Deus da maneira como elas aparecem nas prédicas.

\section{Tabela 1 - Imagens de Deus}

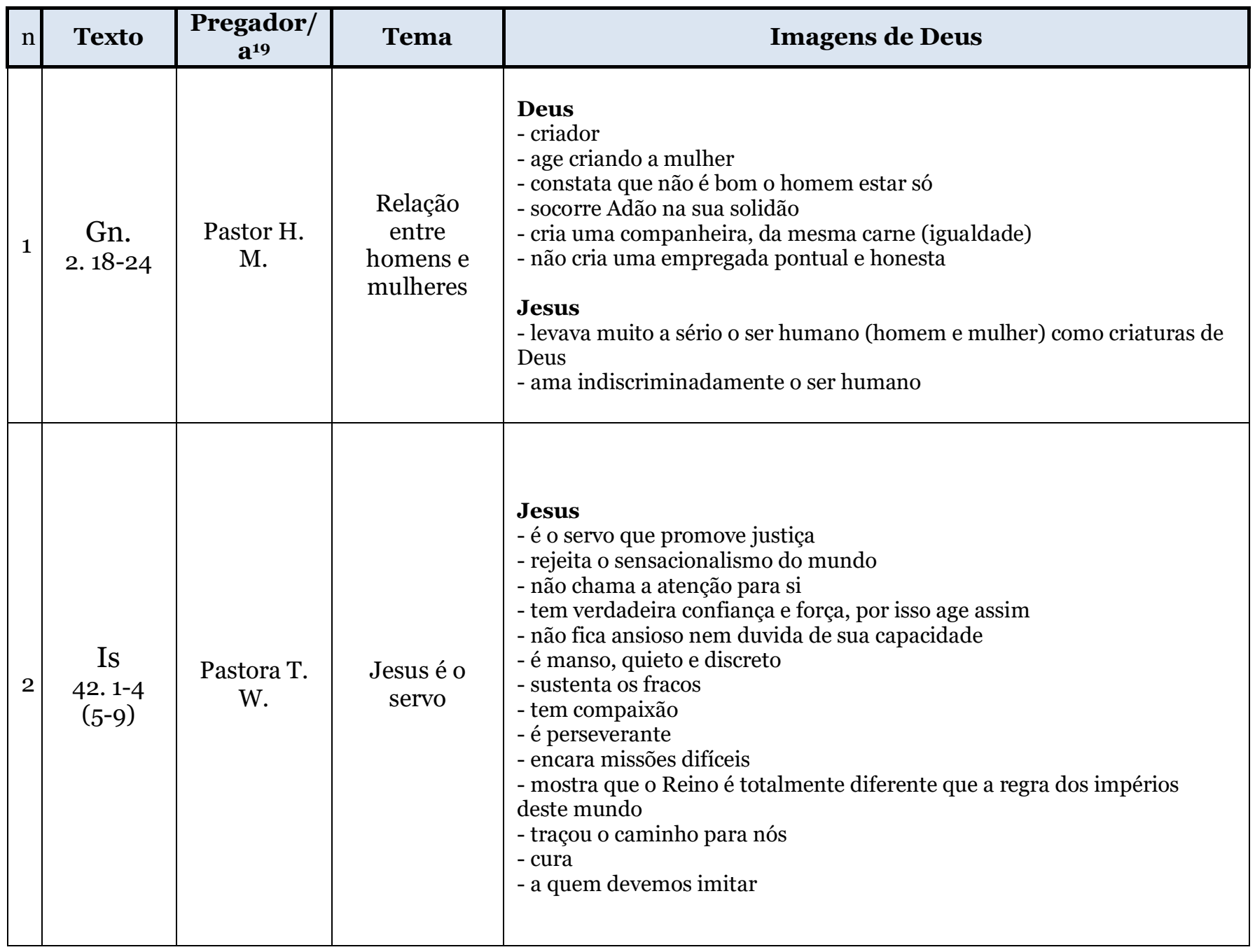

\footnotetext{
${ }^{19}$ Mesmo que seja um site de domínio público, usa-se aqui apenas as iniciais dos/as pregadores/as, como forma de preservação do/a
} autor/a, uma vez que suas prédicas não foram produzidas para fins de uma análise como esta, sobre imagens de Deus na prédica. 


\begin{tabular}{|c|c|c|c|c|}
\hline $\mathrm{n}$ & Texto & $\begin{array}{c}\text { Pregador } \\
/ \mathbf{a}\end{array}$ & Tema & Imagens de Deus \\
\hline 3 & $\begin{array}{c}\mathrm{Am} \\
5 \cdot 6-7 \\
10-15\end{array}$ & $\begin{array}{c}\text { Pastor J. } \\
\text { M. S. }\end{array}$ & $\begin{array}{c}\text { Chamado ao } \\
\text { povo para } \\
\text { mudar de } \\
\text { mentalidade }\end{array}$ & $\begin{array}{l}\text { Deus } \\
\text { - chama para ser profeta da verdade e da justiça } \\
\text { - capacita o profeta para fazer um diagnóstico da vida do povo } \\
\text { - ameaça com juízo e destruição } \\
\text { - quer um povo íntegro e comprometido com a prática da justiça } \\
\text { - salva } \\
\text { - transforma mentes e corações } \\
\text { - fonte de vida } \\
\text { - se compadece } \\
\text { - Deus da esperança } \\
\text { - enviou Jesus Cristo para trazer vida plena e em abundância } \\
\text { - Reino de Deus e sua justiça }\end{array}$ \\
\hline 4 & $\begin{array}{c}\text { Mt } \\
17.1-9\end{array}$ & $\begin{array}{c}\text { Pastor E. } \\
\text { W. }\end{array}$ & Transfiguração & $\begin{array}{l}\text { Na presença de Jesus os discípulos têm } \\
\text { - um encontro com o inexplicável } \\
\text { - com o sagrado } \\
\text { - experimentam o sagrado } \\
\text { - sentiram o céu e a terra se tocando } \\
\text { - uma visão que causa impacto } \\
\text { - sensação boa } \\
\text { - uma pontinha de eternidade } \\
\text { Jesus } \\
\text { - se transfigurou, algo que não conseguimos explica e entender, apenas ter } \\
\text { fé } \\
\text { - envolto em brilho e luz } \\
\text { - filho do Deus vivo sofre } \\
\text { - glória e brilho ligados ao sofrimento e cruz } \\
\text { - sagrado passa pelo sofrimento } \\
\text { - ressurreição } \\
\text { - ressurreição não está desconectada do sofrimento e cruz }\end{array}$ \\
\hline 5 & $\begin{array}{c}\text { Mt } \\
\text { 20. 1-15 }\end{array}$ & $\begin{array}{c}\text { Pastora R. } \\
\text { S. }\end{array}$ & $\begin{array}{c}\text { Justiça de } \\
\text { Deus é } \\
\text { diferente da } \\
\text { justiça } \\
\text { humana }\end{array}$ & $\begin{array}{l}\text { Deus } \\
\text { - o dono da vinha } \\
\text { - foi justo } \\
\text { - não quer que pessoas e famílias passem fome } \\
\text { - não quer o sofrimento } \\
\text { - sua justiça é diferente da humana } \\
\text { - não é um “deus banana”, um deus que aceita tudo, que perdoa e salva de } \\
\text { forma fácil e barata } \\
\text { - sua graça não é barata, mesmo que salvação seja gratuita (Lutero) } \\
\text { - entrega Jesus Cristo por nós } \\
\text { - vontade de Deus é que tenhamos liberdade } \\
\text { - não quer um bando de seguidores/as por conveniência ou medo } \\
\text { - quer pessoas com coragem para defender a justiça e o direito, com } \\
\text { coragem para viver uma vida honesta, fiel aos princípios cristãos, } \\
\text { responsável consigo e a criação } \\
\text { - diante de Deus estamos todos perdidos } \\
\text { - sua graça e justiça nos redime } \\
\text { Jesus } \\
\text { - conta a parábola dos trabalhadores da vinha } \\
\text { - chama a atenção para não sermos preguiçosos e negligentes com a fé e } \\
\text { na aceitação da salvação } \\
\text { - somos chamados a seguir o exemplo de Jesus (vontade de Deus) }\end{array}$ \\
\hline
\end{tabular}




\begin{tabular}{|c|c|c|c|c|}
\hline $\mathrm{n}$ & Texto & $\begin{array}{c}\text { Pregador } \\
/ \mathbf{a}\end{array}$ & Tema & Imagens de Deus \\
\hline 6 & $\begin{array}{c}\text { Mt } \\
\text { 22. } 34-46\end{array}$ & Pastor G. B. & $\begin{array}{c}\text { O grande } \\
\text { mandamento } \\
\text { e o mercado }\end{array}$ & $\begin{array}{l}\text { Amor } \\
\text { - em sentido bíblico não deve ser confundido com simpatia, afeto e paixão } \\
\text { - não reduzido à questão sentimental } \\
\text { - é uma questão da vontade } \\
\text { - o que quero em relação à pessoa próxima } \\
\text { - amor a Deus e ao próximo não é a mesma coisa } \\
\text { Jesus } \\
\text { - fala não somente do amor ao próximo, mas também do amor a Deus } \\
\text { - relaciona os dois mandamentos e mostra que há uma estreita relação } \\
\text { entre eles } \\
\text { - chamou de "mamom" o dinheiro, a riqueza e o lucro } \\
\text { - quer uma determinada mentalidade }\end{array}$ \\
\hline 7 & $\begin{array}{c}\text { Jo } \\
\text { 1. } 1-18\end{array}$ & $\begin{array}{c}\text { Pastor G. } \\
\text { W. }\end{array}$ & $\begin{array}{c}\text { Grande } \\
\text { mistério do } \\
\text { amor } \\
\text { encarnado de } \\
\text { Deus em } \\
\text { nosso meio }\end{array}$ & $\begin{array}{l}\text { Deus } \\
\text { - tem poder } \\
\text { - faz com que o povo experimente libertação e verdadeira recriação } \\
\text { - escolheu as pessoas como filhos/as já antes da criação do mundo } \\
\text { - salvação em Jesus Cristo } \\
\text { - criação foi feita pela poderosa Palavra de Deus } \\
\text { - mistério do eterno Deus que se encarna em nossa realidade de } \\
\text { sofrimento } \\
\text { - ressuscitou Jesus com nova vida que não mais morre } \\
\text { - colocou-o a sua direita para reinar } \\
\text { Jesus } \\
\text { - Palavra se tornou pessoa em Jesus Cristo } \\
\text { - por nós nascido, vivido, crucificado, ressuscitado, subido ao céu e lá } \\
\text { intercedendo por nós e nos preparando lugar eterno na casa de Deus } \\
\text { - nos trata melhor do que uma boa mãe e um bom pai } \\
\text { - ele mesmo nos lava os olhos da fé } \\
\text { - faz o cego ver } \\
\text { - faz com que nele percebamos o próprio Deus e o verdadeiro ser humano } \\
\text { - nos liberta para vivermos como filhos/as de Deus } \\
\text { - anuncia o Evangelho } \\
\text { - fez irromper sinais concretos de justiça e paz, sinais do reino de Deus } \\
\text { - seu jeito de viver foi como luz que brilha na escuridão } \\
\text { - rejeitado e crucificado pelo mundo } \\
\text { - Palavra eterna que está entre nós como Palavra pregada, falada, escrita, } \\
\text { musicada, pintada, esculpida, nas belezas da criação } \\
\text { - visível e experimentável entre nós por meio dos sacramentos } \\
\text { - Palavra ainda não re-conhecida e rejeitada por muitos } \\
\text { - Palavra de Deus está aí, escondida sob a fragilidade de palavras humanas } \\
\text { Espírito Santo } \\
\text { - ilumina pela fé } \\
\text { - quer lavar nossos olhos } \\
\text { - nos certifica de nossa dignidade de filhos/as de Deus } \\
\text { - anima-nos pela promessa da vida eterna } \\
\text { - promessa no batismo } \\
\text { - nos conscientiza da nossa tarefa e do nosso compromisso } \\
\text { - nos aceita por amor insondável } \\
\text { - nos liberta para amarmos incondicionalmente } \\
\text { - nos perdoa } \\
\text { - nos constrange a perdoarmos uns aos outros } \\
\text { - nos capacita e anima a servirmos }\end{array}$ \\
\hline
\end{tabular}




\begin{tabular}{|c|c|c|c|c|}
\hline $\mathrm{n}$ & Texto & $\begin{array}{c}\text { Pregador } \\
/ \mathbf{a}\end{array}$ & Tema & Imagens de Deus \\
\hline 8 & $\begin{array}{c}\text { Jo } \\
11.1-5 ; \\
17-21\end{array}$ & $\begin{array}{c}\text { Pastora C. } \\
\text { B. U. }\end{array}$ & $\begin{array}{l}\text { Conviver } \\
\text { com a } \\
\text { realidade da } \\
\text { morte }\end{array}$ & $\begin{array}{l}\text { Jesus } \\
\text { - irmãs buscam Jesus para comunicar a doença grave do irmão } \\
\text { - atitude de Jesus } \\
\text { - amava muito esta família } \\
\text { - antecipa algo que virá a acontecer no futuro } \\
\text { - demora a chegar em Betânia } \\
\text { - não se faz presente no sepultamento de Lázaro } \\
\text { - Marta desabafa: Se tivesses estado aqui, meu irmão não teria morrido } \\
\text { - nada disse, só ouviu } \\
\text { - no ouvir solidarizou-se com a dor e o sofrimento } \\
\text { Deus } \\
\text { - meu Deus, cujo nome é exaltado, louvado, porque faz maravilhas e } \\
\text { executas os conselhos antigos, fieis e justos } \\
\text { - a vida é sempre um presente de Deus } \\
\text { - viver a partir da eternidade é entender a vida como graça de Deus } \\
\text { - nada poderá nos separar do amor de Deus }\end{array}$ \\
\hline 9 & $\begin{array}{c}1 \text { Co } \\
\text { 1. } 18-25\end{array}$ & Pastor J. K. & $\begin{array}{c}\text { Em Jesus } \\
\text { Cristo, Deus } \\
\text { nos mostra } \\
\text { radicalmente } \\
\text { outra lógica } \\
\text { para a vida: o } \\
\text { reino }\end{array}$ & $\begin{array}{l}\text { Jesus } \\
\text { - Deus encarnado que morreu na cruz } \\
\text { - faz contato com escravos, mulheres e crianças } \\
\text { - sofrimento de Cristo na cruz, tudo muda } \\
\text { Deus } \\
\text { - aproximou-se tanto da sua criação que se tornou humano } \\
\text { - acreditar em Deus feito carne é loucura } \\
\text { - o divino é visto como tão perfeito que não pode misturar-se com o } \\
\text { humano } \\
\text { - entra na história e se aproxima da humanidade de forma diferente, } \\
\text { absurda } \\
\text { - em Jesus Cristo, mostra seu lado humano } \\
\text { - vem ao nosso encontro } \\
\text { Jesus } \\
\text { - assume a morte na cruz } \\
\text { - sua ação é tão grande que assusta e maravilha } \\
\text { - o absurdo da encarnação, morte e ressureição de Jesus faz com que a fé } \\
\text { em Corinto cresça } \\
\text { - rompe-se a lógica convencional e o amor é a medida } \\
\text { - ricos e pobres, escravos e livres, gregos e judeus podem celebrar juntos } \\
\text { - mostrar o amor de Deus manifesto em Jesus entre os pobres, escravos, } \\
\text { os sofridos de hoje }\end{array}$ \\
\hline
\end{tabular}

Fonte: Dados da pesquisa, 2016

\section{Algumas considerações sobre esta análise:}

Como já expresso, não se pretende com esta análise conclusivamente definir e conceituar imagens e imaginários de Deus presentes nas prédicas da IECLB, muito menos definir as prédicas. Temos aqui apenas um exemplo, um recorte de 
prédicas e de imagens e imaginários de Deus expressos para poder relacionar com aquilo que foi abordado nos dois pontos anteriores do artigo. Alguns aspectos merecem uma reflexão.

Primeiramente, chama atenção a variedade de conceitos, atributos e ações a respeito de Deus. Jesus é alguém que faz! Nesse sentido, há uma variedade conceitual nas imagens de Deus. Por vezes, se faz referências a Deus a partir dos outros textos bíblicos lidos no culto, ou se considera o conhecimento bíblico do ouvinte. Ao mesmo tempo em que há uma variedade, os conceitos e atributos são de alguma maneira abrangentes, generalizantes, replicando conceitos bíblicos e teológicos: vontade de Deus, justiça de Deus, o amor de Jesus, morreu por nós, sagrado, palavra eterna, amor, etc. Fala-se, p. ex., de seguir o exemplo de Jesus, hoje (nas prédicas 2, 5 e 6 aparece essa tônica de forma explícita), como que trazendo o exemplo para um hoje. Mas que hoje é esse? Quase nada aparece sobre como se caracteriza esse contexto. Que contexto, que hoje, que vida é esta? É a vida da comunidade? É o contexto das grandes cidades, onde a desigualdade social é tão visível? É o contexto onde “Deus é brasileiro”, sincrético, inculturado, com jeitos e manias brasileiras, um Deus um tanto distante e vingativo? Parece que não! A imagem de Deus permanece apenas na ideia, na Palavra, no texto. É uma imagem fixa ao texto. Pode-se dizer que o Deus pregado nas prédicas analisadas tende a permanecer imune à cultura, muito diferente daquilo que a cultura faz quando livremente se apropria das imagens e dos imaginários de Deus, reinventa o próprio Deus. Poderíamos perguntar: da mesma forma como Jesus é pregado de forma concreta nas prédicas, não se poderia tornar o hoje e o contexto mais concreto e vivencial? Será que o contexto não tornaria Jesus e Deus mais vívidos e conceitualmente menos abrangentes? A pregação como viva vox Evangelii não deveria encarnar-se em meio à vida concreta de hoje? Respondendo à pergunta do artigo sobre a influência das imagens na pregação, parece que as imagens de Deus e a dinâmica com que imagens e imaginários de Deus são criados não influenciam a prédica, pelo menos estas. Os Cristos crucificados da TdL talvez tenham conseguido fazer esse diálogo. Ali Cristo ganha contexto e o contexto ganha Cristo. 
Neste mesmo rumo, outro aspecto que merece reflexão é o fato de que mais do que dizer que é Deus, as prédicas apontam para algo que Deus faz: Deus cria, chama, capacita, transforma, se compadece, pune, tem uma vontade, tem um Reino, não quer o sofrimento, etc. (nas prédicas 1,3, 5, 7 e 9, p. ex.) Ao mesmo tempo, imagem de Deus é uma imagem que eu chamaria bíblico-teológica. Uma imagem mais para entender do que para ver, identificar em meio à vida. Parece que toda a ação de Deus fica para lá, restrita ao texto. Mesmo quando se fala da vida, se valoriza mais conceitos do que experiências e vivências. No conjunto, há certa redundância (obviedade?) nesta imagem bíblico-teológica de Deus: Deus, o criador, manifestou sua vontade justa e boa em Jesus Cristo, encarnando-se, vivendo, morrendo e ressuscitando, para a salvação, e, agora, as pessoas, a Igreja, devem corresponder a esse chamado, vivendo o amor, a justiça. A comunidade já não sabe disso? Uma das prédicas fala da relação de Jesus com as irmãs de Lázaro. É quase o único momento em que se relata uma relação, mesmo que seja com irmãs, no texto. Parece haver por detrás desta redundância teológica uma necessidade de mostrar Deus como ele é “de fato", através do sistema da linguagem, no sentido que Wolff aponta. Deus não pode ser transmitido através da dinâmica fascinante e falível da imagem, como substituição, mas tão somente como Palavra, fechado dentro de conceitos teológicos.

Um último aspecto que chama atenção: nas prédicas analisadas, fala-se bastante a respeito de Deus e de Jesus Cristo. A respeito do Espírito Santo, aparece algo apenas em uma prédica (prédica 7). Quando se fala de Jesus Cristo, se fixa nos feitos no Evangelho ou também em ideias teológica, p. ex. "Deus encarnado que morreu na cruz" ou "anuncia o Evangelho". Novamente aqui, poderíamos refletir que há uma tendência à conceituação. Como a ação do Espírito Santo é dinâmica e livre - diria que está mais para aquilo que Wolff definiria como o sistema imagem, visual, espacial, fruto da imaginação, muito mais rudimentar, mas surpreendentemente e impressionante, e que tem o poder mágico de fazer viver os mortos e fazer existir o céu sobre a terra (Wolff) - pouco se ousa falar sobre o Espírito Santo. 


\section{Uma conclusão}

Certamente podemos discutir muito a respeito destas imagens de Deus presentes nas nove prédicas analisadas e sua relação com o contexto. As imagens de Deus e sua implicância para a vida, nestas nove prédicas, postadas em um site, são generalizantes e fechadas dentro de conceitos teológicos, mesmo quando dizem algo que Deus faz. Há poucos relatos de situações vivenciais da comunidade, p. ex. Mesmo a narratividade dos textos bíblicos é transformada em ideia e conceito. Ou seja, são imagens que mais falam sobre ideias e ações de Deus, e menos sobre a articulação de Deus para dentro da vida concreta da comunidade, crítica já feita pela Nova Homilética. Se fala concretamente de Deus, mas pouco de um contexto concreto. Talvez, tendo sido a prédica escrita apenas para o site, fez com que não se levasse em consideração o caso concreto da comunidade, como já observamos acima. Por outro lado, conhecendo o contexto de pregação da IECLB, não sei se as prédicas pregadas no púlpito diferem muito das encontradas no site, infelizmente. Uma pesquisa, tomando prédicas de comunidades poderia investigar esta minha hipótese.

Isto nos leva a pensar o seguinte: em um contexto de "Deus brasileiro", não estaria a pregação da IECLB ainda fixada na imagem de um Deus bíblico, estático, distante? Em que medida o Deus que se imiscui na vida brasileira não deveria ser mais pregado no púlpito? Ou, se isto for escandaloso demais para algumas tradições: como esta cultura que tão livre, dinâmica e arriscadamente incultura e embaralha imagens e imaginários de Deus poderia ser aproveitada na pregação evangélico-luterana brasileira? Estou convencido de que o contexto cultural e religioso impregnado de imagens de Deus influencia não só o imaginário das pessoas, mas também a fé, também dos evangélicos-protestantes membros da IECLB. Quando estamos falando de Deus, Jesus Cristo e Espírito Santo, as pessoas, livremente fazem suas associações e imaginações de Deus e estas terão os mais diversos desdobramentos em suas vidas e em sua fé. As pessoas criam imagens e imaginários de Deus, in-dependentes do púlpito. Isso só teremos como comprovar, 
porém, no momento em que ouvirmos os ouvintes das prédicas, tarefa para um próximo artigo. Quais imagens e imaginários de Deus são engendrados durante e após cada sermão?

As imagens de Deus presentes nas prédicas analisadas são imagens bíblicoteológicas “corretas”, e que correspondem a uma teologia evangélica-luterana, e a um comprometimento com o contexto social de vulnerabilidade onde a igreja está inserida. Muito diferentes de imagens oriundas da Teologia da Prosperidade, as imagens de Deus, aqui, têm relação com a justiça social, a lógica de Deus oposta ao mundo, o amor a Deus e ao próximo como algo vivencial, com um Deus, boa mãe e bom pai, que cuida e se importa com os seres humanos. Mesmo assim, são imagens por demais teológicas, racionalizantes, aparentemente com pouco relevância para dentro da vida concreta. São uma espécie de imagens domesticadas de Deus, como diria Alberto Kelsey (KELSEY, 2012, p. 21ss.). Scott Hoezee diria que falta realidade concreta para estas prédicas. "Sermons need not more flowery talk, not more words, not more slogans or aphorisms or bromides or statements: they need mor reality. The congregation needs to see itself in the picture the sermon is sketching” (HOEZEE, 2014, p. 17).

Gostaria ainda de ousar a pensar - na homilética - a teologia da cruz de Lutero em diálogo com a Teologia da Libertação, buscando no Cristo que se identifica com a vida das pessoas, o Crucificado e o Ressurreto, expressões e imagens para falar de Deus na pregação da IECLB, de forma que a Palavra de Deus ganhe livremente vida e transforme o mundo, como diz Lutero.

Yo predicaré, enseñaré, escribiré, pero no forzaré a nadie, porque la fe necesita nacer libremente, sin coerción. Vean el ejemplo de mi propia persona. Yo me opuse a las indulgencias y a todos los papistas sin el uso de la fuerza. Yo simplemente enseñé, prediqué y escribí la Palabra de Dios, y nada más. Y mientras yo dormía o bebía cerveza con mis amigos Phillip Melanchton y Nicholas von Amsdorf, la Palabra de Dios incomodaba fuertemente al papado [...] Yo nada hice; la Palabra lo hizo todo sola. (SOUZA, 2010).20

\footnotetext{
${ }^{20}$ Sermão de Martim Lutero, de 1522 (Luther's Works 51, 77), referido em SOUZA, Mauro B. de. La prédica en Martín Lutero: algunas implicaciones para la predicación cristiana latinoamericana de la actualidade. In: LÓPEZ RUBIO, Amós (Org.). Y el verbo se hizo carne: desafíos actuales a la predicación evangélica en la América. La Habana: Editorial Caminos, 2010, p. 116.
} 
Há nesta afirmação de Lutero sobre a pregação algo daquilo que vimos nas considerações sobre imagem e imaginário, no ponto dois deste artigo. Assim como as imagens e os imaginários em seu caráter simbólico transgridem e transcendem aquilo que representam, também a prédica, como “substituto” e “intermediário” da Palavra de Deus age e influencia livremente quem a escuta e quem a "vê". Ou seja, também no discurso, não temos controle e domínio sobre as "imagens" de Deus e sua potencialidade de influenciar. Considerando isto, não estaria na hora de ousarmos "imaginar" Deus de forma mais livre, aberta e ampla, em correspondência com as tantas imagens e imaginários "subcontrários" de Deus presentes na cultura brasileira, e, assim, aproximar este Deus Absconditus da vida concreta das pessoas deste contexto? Uma prédica, onde a imagem de Deus seja de um Deus com o rosto do Brasil?

\section{REFERÊNCIAS}

ARAÚJO, João Dias. O Cristo brasileiro: a teologia do povo. São Paulo: ASTE, 2012.

BEISE ULRICH, Claudete. 2017 in lateinamerikanisch-lutherischer Perspektive: einige Gedanken. Artigo não publicado.

CAMPOS, Leonido Silveira. Teatro, templo e mercado: organização e marketing de um empreendimento neopentecostal. 2. Ed. Petrópolis/São Paulo/São Bernardo do Campo: Vozes/Simpósio/UMESP, 1999.

COSTA, Mozart A. B. da; PASSOS, Maria José S. T. Imaginária religiosa brasileira: em busca de uma arqueologia da beleza. In: MARIANI, Ceci B.; VILHENA, Maria A. Teologia e arte: expressões de transcendência, caminhos de renovação. São Paulo: Paulinas, 2011, p. $123-134$.

CUNHA, Magali do Nascimento. Religião na esfera pública: a tríade mídia, mercado e política e a reconstrução da imagem dos evangélicos brasileiros na contemporaneidade. In: REBLIN, Iuri A.; VON SINNER, Rudolf (Org.). Religião e sociedade: desafios contemporâneos. São Leopoldo: Sinodal/EST, 2012, p. 173ss.

DAMATTA, Roberto. Carnavais, malandros e heróis: para uma sociologia do dilema brasileiro. Rio de Janeiro: Rocco, 1997.

DEBORD, Guy. La sociedade del espetáculo. Valencia: Pre-Textos, 2000. 
DROOGERS, André. A Religiosidade Mínima Brasileira. Religião e Sociedade, n. 14, vol. 2, Rio de Janeiro, 1987, p. 63ss.

EBELING, Gerhard. O pensamento de Lutero: uma introdução. São Leopoldo: Sinodal, 1988.

Evangelische Kirche Lutherischen Bekenntnisses in Brasilien (IECLB), In: http://www.mission-einewelt.de/index.php?id=507. Acesso em 10.06.2012.

FRETTLÖH, Magdalene. Wenn (Schrift-)Worte sich in Bilder einschreiben.

Theologische Zeitschrift, Basel, ano 69, n. 3, p. 238-265, 2013.

HIGUET, Etienne A. Imagens e imaginários: subsídios teórico-metodológicos para a interpretação das imagens simbólicas e religiosas. In: NOGUEIRA, Paulo Augusto de Souza (Org.). Religião e linguagem: abordagens teóricas interdisciplinares. São Paulo: Paulus, 2015, p. 15-62.

HOEZEE, Scott. Actuality: Real Life Stories for Sermons That Matter. Nashville: Abingdon Press, 2014.

GÖTTINGER PREDIGTEN IM INTERNET. Disponível em: <http://www.predigten.uni-goettingen.de>. Acesso em: 02/05/2015.

KELSEY, David H. Picturing God Theologically in a Fragmented World. In: HOGAN, Lucy; PLEIZIER, Theo (Org.). Preaching as picturing God in a fragmented world. Delft: Eburon Academic Publishers, 2012, p. 21ss.

KLEIN, Alberto. Imagens de culto e imagens da mídia: interferências midiáticas no cenário religioso. Porto Alegre: Sulina, 2006.

LEMOS, Carolina Teles. Religião e gênero no cinema. In: MOREIRA, Alberto da Silva; LEMOS, Carolina T.; QUADROS, Eduardo de Gusmão (Org.). A religião na mídia e a mídia na religião. Goiânia: América, 2012, p. 59ss.

RENDERS, Helmut. Artefatos, imagens e logotipos como linguagens da religião: uma proposta multidisciplinar do estudo da cultura visual religiosa brasileira. In: NOGUEIRA, Paulo Augusto de Souza (Org.). Religião e linguagem: abordagens teóricas interdisciplinares. São Paulo: Paulus, 2015, p. 61-87.

SOUZA, Mauro B. de. La prédica en Martín Lutero: algunas implicaciones para la predicación cristiana latinoamericana de la actualidade. In: LÓPEZ RUBIO, Amós (Org.). Y el verbo se hizo carne: desafíos actuales a la predicación evangélica en la América. La Habana: Editorial Caminos, 2010, p. 116ss.

STEIL, Carlos A. O sertão das romarias: um estudo antropológico sobre o santuário de Bom Jesus da Lapa. Petrópolis: Vozes, 1996.

TEIXEIRA, Faustino L. C. A gênese das CEBs no Brasil: elementos explicativos. São Paulo: Paulinas, 1988. 
WOLFF, Francis. Por trás do espetáculo: o poder das imagens. In: NOVAES, Adauto (Org.). Muito além do espetáculo. São Paulo: Senac, 2005, p. 20 ss.

ZWETSCH, Roberto E. O Cristo torturado da América Latina: reflexões sobre arte e teologia a partir das esculturas de Guido Rocha. In: SCHAPER, Valério G.; WESTHELLE, Vítor, OLIVEIRA, Kathlen L. de; GROSS, Eduardo (Orgs.). Deuses e ciências na América Latina. São Leopoldo: Oikos/EST, 2012, p. 73-93. 